Article

\title{
Parallel Resonance Mechanism Analysis and Suppression of Inductance-Capacitance-Inductance Grid-Connected Inverters
}

\author{
Haijun Tao ${ }^{\circledR}$, Yousong Zhou, Guopeng Zhang * and Zheng Zheng \\ School of Electrical Engineering and Automation, Henan Polytechnic University, Jiaozuo 454003, China; \\ taohj99@hpu.edu.cn (H.T.); z2410767638@163.com (Y.Z.); zhengzh@hpu.edu.cn (Z.Z.) \\ * Correspondence: hpoyz@163.com; Tel.: +86-0391-3987573
}

Received: 13 February 2019; Accepted: 28 April 2019; Published: 30 April 2019

check for updates

\begin{abstract}
The resonance problem of multi-paralleled grid-connected inverters with inductance-capacitance-inductance (LCL) filters is a core matter which bothers the safety and stability operation of new energy distribution networks. Based on the impedance model of the paralleled system of two inverters, the influence of inverters on grid-connected current was analyzed through the superposition principle, and the grid-connected current was decomposed. The resonant mechanism generated by interactive current and the common current was studied, and the resonance frequency characteristics were compared and analyzed by a paralleled system using the same and differently rated power inverters. Based on the resonance frequency generated by interactive current, a digital notch filter was introduced into the traditional capacitance current active damping control scheme, which realized the non-static control of base wave signal and satisfied the standard of multi-paralleled grid-connected inverters with LCL filters. Finally, simulation results verified the correctness and validity of the proposed strategy.
\end{abstract}

Keywords: multi-paralleled inverters; different rated power; digital notch filter; resonance interaction

\section{Introduction}

In recent years, with the increasingly prominent energy and environmental problems, renewable energy grid-connected generation technology has received more and more attention, and grid-connected inverters are the core component of wind energy, photovoltaic power generation, as well as other distributed generation systems [1,2]. Compared with L-type filters, inductance-capacitance-inductance (LCL)-type filters have a strong capability to suppress high-frequency harmonics and have the advantages of small size and low cost. They are widely used in all kinds of grid-connected equipment [3]. In practical applications, single LCL grid-connected inverters can meet the grid-connected requirements $[4,5]$. However, when multiple LCL grid-connected inverters operate simultaneously in parallel, the system will have resonance and instability. The resonance problem of parallel operation of multiple grid-connected inverters has affected the large-scale popularization and application of new energy grid-connected generation technology [6,7]. Therefore, it is of great significance to study the grid-connected resonant principle of multiple grid-connected inverters and its resonant suppression strategy.

To solve the problem of resonance in parallel systems of multiple grid-connected inverters, domestic and foreign scholars have carried out many studies. Reference [8] proposed a modeling and control method for a multi-grid-connected inverter system and points out that when $\mathrm{N}$ grid-connected inverters are parallel connected, the equivalent grid impedance of a single grid-connected inverter in the system can be equivalent to $\mathrm{N}$ times the actual grid impedance. References [9-11] analyzed the influence 
of grid impedance on the LCL resonance characteristics of multi-grid-connected inverters, although these methods analyze the multi-grid-connected inverters. The resonance mechanism of parallel inverters is not considered, and the interaction between grid-connected inverters is not considered. In order to discuss the interaction between grid-connected inverters, a direct analysis method based on equivalent grid impedance was proposed in [12]. The resonance frequency characteristics and stability of the system are analyzed. In [13], the interaction under weak grid conditions was discussed, the concepts of interactive current and common current are proposed, and the stability of the system into interactive stability and common stability is also analyzed; discontinuous pulse width modulation (DPWM) for a grid-connected inverter system using an LCL-filter was proposed [14], and a virtual impedance-based bandwidth control method for multi-parallel harmonic-compensation grid-connected inverters is proposed [15]. On the basis of references [12-15], reference [16] revealed the resonance phenomenon caused by the interactive current, and analyzes the influence of the interactive resonance between inverters on the resonance and dynamic characteristics of the system. However, in [12-16] it was assumed that the parameters and control strategies of all grid-connected inverters are the same. In practical applications, due to the difference of grid-connected capacity, output current and LCL filter parameters, the resonance frequency and the number of resonance peaks of grid-connected systems with multiple grid-connected inverters will be directly affected, which makes it difficult to analyze the resonance characteristics of parallel systems with multiple inverters. Therefore, the literature on parallel systems of different capacity inverters is rarely involved [17]. The passive damping is a convenient possibility to tackle the resonance problem at the cost of overall system efficiency. In contrast, active damping does not require any dissipation elements, and a notch filter based active damping without the requirement of additional sensors is introduced [18].

In order to deeply study the resonance mechanism of multi-grid inverter parallel system, this paper takes two grid-connected inverters as an example and analyzes the influence of each inverter on grid-connected current using the superposition theorem. The grid-connected current was decomposed, and the resonance frequency point characteristics of the parallel system of the same and different capacity grid-connected inverters were compared and analyzed. A digital notch filter was designed based on the resonant frequency points generated by the interactive current in the parallel system of multi-inverters. It was introduced into the traditional capacitive current feedback active damping control to realize the suppression of the multi-resonant frequency points in this system and meet the grid-connected requirements of the system. Finally, the parallel system simulation models of the same and differently rated capacity inverters were built in the MATLAB/Simulink simulation platform (2017a, MathWorks, Natick, MA, USA), which verifies the feasibility of the proposed strategy for parallel operation of multi-grid-connected inverters in the weak power grid.

\section{Structure and Control Model of Two Inverters Parallel System}

\subsection{Parallel Topology of Two Grid-Connected Inverters}

The parallel topology of the two inverters is shown in Figure 1. Each group of inverter units is connected to the point of common coupling (PCC) through the LCL filter, and connected to the grid via the grid impedance. In Figure $1, Z_{1 n}, Z_{C n}$, and $Z_{2 n}$ are inverter side inductance, filter capacitor capacitance and grid side inductance of the inverters $n(n=1,2)$, respectively; $Z_{g}$ is the inductance of the grid; $U_{d c n}$ is the direct current (DC) side voltage of the inverters $n ; U_{g}$ is the grid voltage; $u_{0 n}$ is the output voltage of the inverters $n, I_{2 n}$ is the output current of the inverters $n$, and $I_{g}$ is the total current of the grid.

$$
Z_{1 n}=s \cdot L_{1 n}, Z_{2 n}=s \cdot L_{2 n}, Z_{C n}=\frac{1}{s \cdot C_{n}}
$$




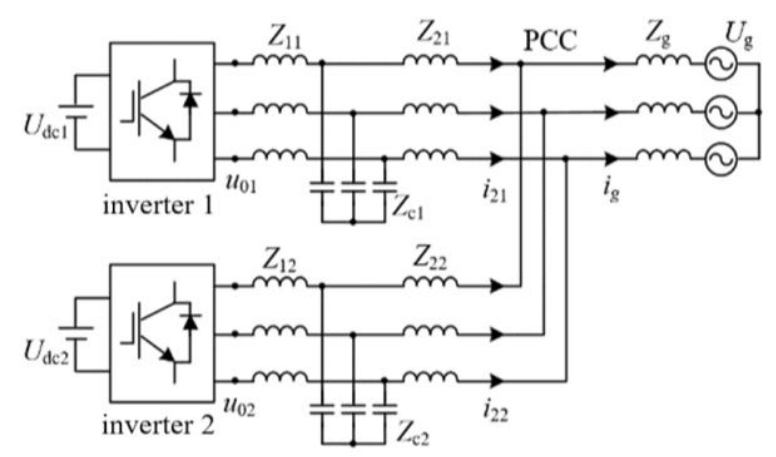

Figure 1. Parallel operation of two grid-connected inverters.

\subsection{Stability Analysis of Single Grid-Connected Inverter}

The current loop control structure of a single grid-connected inverter is shown in Figure 2. A single grid-connected inverter was connected to the grid by independent active capacitive current feedback. For a grid-connected inverter, the primary objective is to control the grid-connected current $i_{2 n}$ to synchronize with the grid voltage $U_{g}$ and to track its amplitude to the given value $I_{2 n}{ }^{*}$. $U_{g}$ phase is usually obtained by phase-locked loop (PLL), $I_{2 n}{ }^{*}$ is generated by the external voltage loop, and $H_{2 n}$ is the sampling coefficient of grid-connected current. The sampling signal of $I_{2 n}$ is compared with its reference value $I_{2 n}{ }^{*}$ and the error signal is fed into the current regulator $G_{i}(s)$. Active damping of the resonant peak of LCL filter is realized by feedback capacitive current $i_{C n}$, and $H_{1 n}$ is capacitive current feedback coefficient. The modulation wave $u_{M}$ can be obtained by subtracting the feedback signal $u_{i C}$ of $i_{C n}$ from the output $u_{r}$ of the controller $G_{i}(s)$. If the damping suppression is not used in a single grid-connected inverter, then:

$$
G_{0}(s)=\frac{i_{2}(s)}{u_{01}(s)}=\frac{1}{s^{3} C L_{1}\left(L_{2}+L_{g}\right)+s\left(L_{1}+L_{2}+L_{g}\right)}
$$

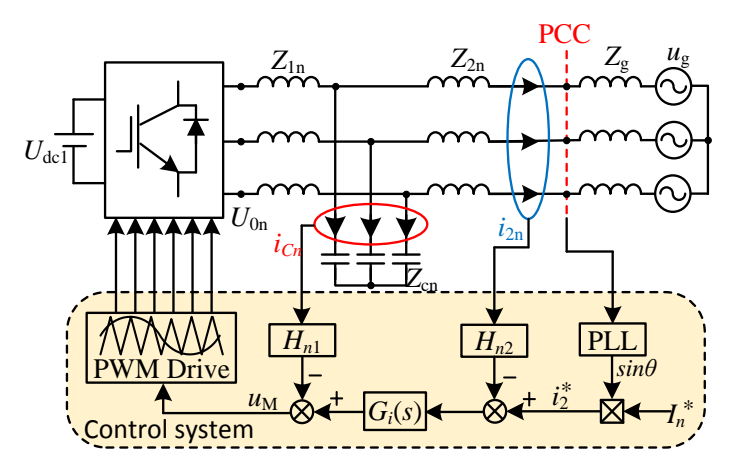

Figure 2. Basic configuration of a single grid-connected inverter.

According to Figure 2, the current loop s-domain control model in the $d q$ coordinate system of the inverter can be derived, as shown in Figure 3. $K_{P W M}$ is the transfer function from modulation signal $u_{M}$ to output voltage $u_{01}$ of the inverter bridge.

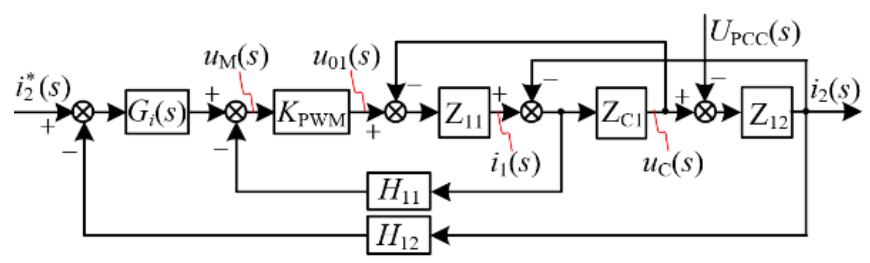

Figure 3. Configuration of single-current loop digital control strategy. 
The loop gain of output current $i_{2}$ from Figure 3 is:

$$
T(s)=\frac{H_{i 2} K_{P W M} G_{i}(s)}{s^{3} C L_{1}\left(L_{2}+L_{g}\right)+s^{2} K_{P W M} C H_{i 1}\left(L_{2}+L_{g}\right)+s\left(L_{1}+L_{2}+L_{g}\right)}
$$

The transfer function from the output voltage $u_{01}$ to the output current $i_{2}$ of the inverter bridge is as follows:

$$
G(s)=\frac{i_{2}(s)}{u_{01}(s)}=\frac{1}{s^{3} C L_{1}\left(L_{2}+L_{g}\right)+s^{2} K_{P W M} C H_{i 1}\left(L_{2}+L_{g}\right)+s\left(L_{1}+L_{2}+L_{g}\right)}=G_{0}(s) G_{a}(s)
$$

From Equations (2) and (4), it can be seen that the influence of active damping control strategy on single grid-connected inverter is as follows:

$$
G_{a}(s)=\frac{s^{3} C L_{1}\left(L_{2}+L_{g}\right)+s\left(L_{1}+L_{2}+L_{g}\right)}{s^{3} C L_{1}\left(L_{2}+L_{g}\right)+s^{2} K_{P W M} C H_{i 1}\left(L_{2}+L_{g}\right)+s\left(L_{1}+L_{2}+L_{g}\right)}
$$

From Equations (2) and (5), a Bode diagram can be plotted as shown in Figures 4 and 5.

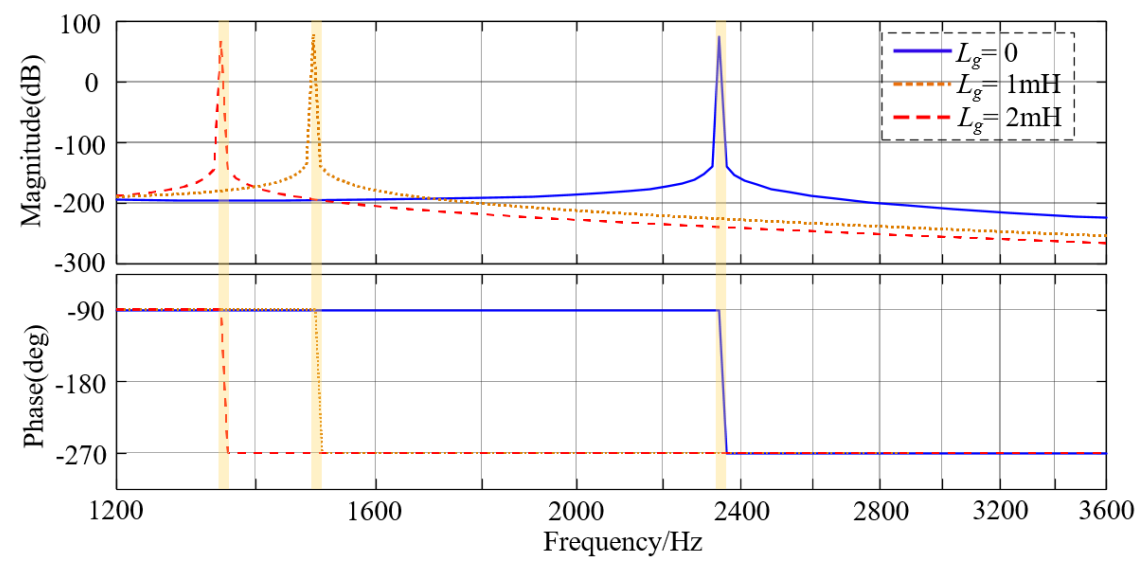

Figure 4. Bode diagram of $G_{0}$.

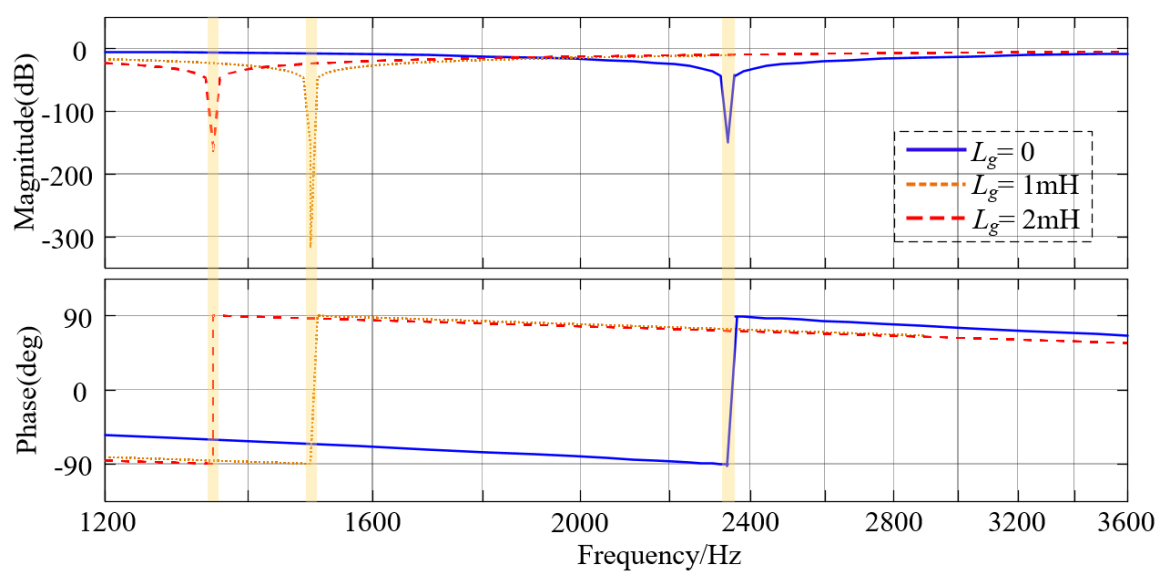

Figure 5. Bode diagram of $G_{a}$.

From the analysis of Figures 4 and 5, it can be seen that when the impedance $L_{g}$ of the power grid increased gradually, the resonance frequency of the system moved to the low frequency band, and the damping suppression effect of active damping also moved and corresponded to it one by one. This is 
due to the fact that the capacitive current feedback coefficient $H_{i 1}$ can still damp the resonance of the system under the condition of satisfying the interval range [19].

$$
10 \frac{G_{M}}{20} \frac{2 \pi f_{c} L_{1}}{K_{P W M}} \leq H_{i 1} \leq \frac{2 \pi L_{1}\left(f_{r}^{2}-f_{c}^{2}\right)\left[f_{c}^{2}-f_{0} \sqrt{\left.\left(10^{\frac{T_{f o}}{20}} f_{0}\right)^{2}-f_{c}^{2} \tan P_{M}\right]}\right.}{K_{P W M} f_{c}\left[f_{c}^{2} \tan P_{M}+f_{0} \sqrt{\left(10^{\frac{T_{f o}}{20}} f_{0}\right)^{2}-f_{c}^{2}}\right]}
$$

It can be seen that although the resonance frequency of the single inverter designed under ideal conditions is offset when it is connected to the grid under weak grid conditions, the active damping of capacitive current feedback will still have a damping suppression effect on the resonance of the system and make the system run stably.

When a single grid-connected inverter is connected to the grid, the single resonance peak generated by the interaction between LCL filter and power grid can be effectively suppressed by using the traditional capacitive current feedback active damping method. When multiple inverters are running in parallel at the same time, due to the existence of mutual resonance between inverters, resonance or instability will appear in the system.

\section{Modeling and Resonance Analysis of Two Inverters Parallel System}

\subsection{Impedance Model of Parallel System}

For the system, the grid voltage $U_{g}$ can be regarded as a disturbance, and it has no effect on the damping of the resonant peak of the LCL filter. To facilitate the analysis of the relationship between the two inverters, the output voltage $u_{0 n}$ of the inverter bridge can be equivalent to a voltage source, and the system control block diagram can be simplified to Figure 6a. The parallel system of two inverters is a multi-input and multi-output system, in which $u_{0 n}$ is the input variable and $i_{2 n}$ is the output control variable. Because inverters 1 and 2 adopt the same circuit structure and control mode, this paper takes the grid-connected current $i_{21}$ of inverters 1 as an example to analyze. Because a group of inverters operate in parallel, the output voltage $u_{0 n}$ of each group of inverters will affect the grid-connected current $i_{21}$. The relationship between grid-connected current $i_{21}$ and output voltage $u_{0 n}$ of the inverter bridge is analyzed by the superposition principle.

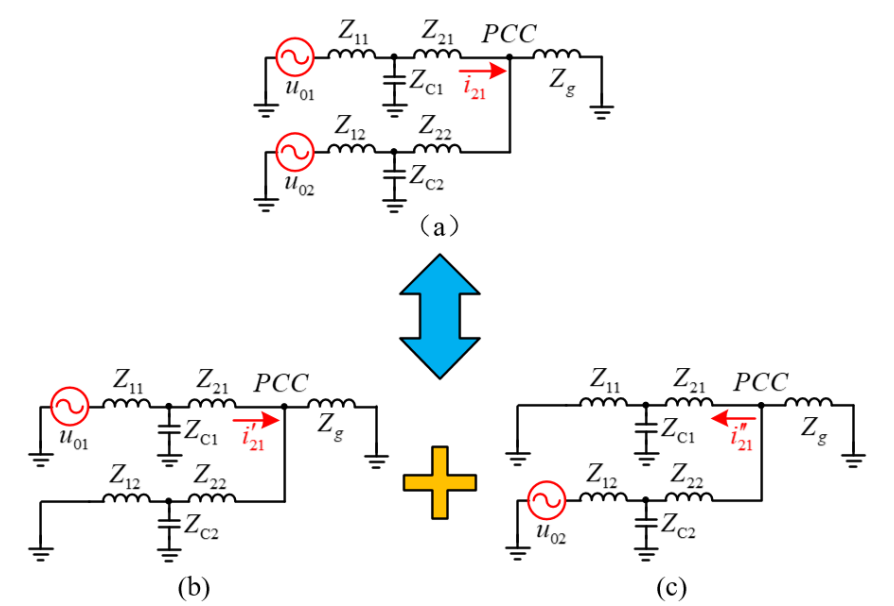

Figure 6. Circuit based on the superposition principle for paralleled inverters. (a) Equivalent circuit of two inverters with inductance-capacitance-inductance (LCL)-filter; (b) equivalent circuit when $u_{02}=0$; and (c) equivalent circuit when $u_{01}=0$.

As shown in Figure $6 \mathrm{~b}, \mathrm{c}$, the system can be divided into two parts: one is the effect of the output voltage $u_{01}$ of inverter bridge 1 on the grid-connected current $i_{21}$; the other is the effect of the output 
voltage $u_{02}$ of inverter bridge 2 on the grid-connected current $i_{21}$. Therefore, for a multi-inverter parallel system, there is an interaction between inverters.

From Figure $6 \mathrm{~b}, \mathrm{c}$, the transfer function between the output voltage $u_{0 n}$ of the inverter bridge and the grid-connected current $i_{21}$ can be obtained as follows:

$$
\left\{\begin{array}{l}
G_{11}=\frac{i_{21}^{\prime}}{u_{01}}=\frac{Z_{c 1}\left(N+2 Z_{g} P\right)}{2\left[M \times N+Z_{g}(M \times P+N \times Q)\right]}+\frac{Z_{c 1} N}{2\left[M \times N+Z_{g}(M \times P+N \times Q)\right]} \\
G_{12}=\frac{i^{\prime \prime}{ }_{21}}{u_{02}}=-\frac{Z_{c 2}\left(M+2 Z_{g} Q\right)}{2\left[M \times N+Z_{g}(M \times P+N \times Q)\right]}+\frac{Z_{c 2} M}{2\left[M \times N+Z_{g}(M \times P+N \times Q)\right]}
\end{array}\right.
$$

where:

$$
\left\{\begin{array}{l}
M=Z_{L 11} Z_{L 21}+Z_{L 11} Z_{c 1}+Z_{L 21} Z_{c 1} \\
N=Z_{L 12} Z_{L 22}+Z_{L 12} Z_{c 2}+Z_{L 22} Z_{c 2} \\
P=Z_{L 12}+Z_{c 2} \\
Q=Z_{L 11}+Z_{c 1}
\end{array}\right.
$$

Similarly, the transfer function between the output voltage $u_{0 n}$ of the inverter bridge and the grid-connected current $i_{22}$ can be obtained as follows:

$$
\left\{\begin{array}{l}
G_{21}=\frac{i^{\prime} 22}{u_{01}}=-\frac{Z_{c 1}\left(N+2 Z_{g} P\right)}{2\left[M \times N+Z_{g}(M \times P+N \times Q)\right]}+\frac{Z_{c 1} N}{2\left[M \times N+Z_{g}(M \times P+N \times Q)\right]} \\
G_{22}=\frac{i^{\prime \prime} 22}{u_{02}}=\frac{Z_{c 2}\left(M+2 Z_{g} Q\right)}{2\left[M \times N+Z_{g}(M \times P+N \times Q)\right]}+\frac{Z_{c 2} M}{2\left[M \times N+Z_{g}(M \times P+N \times Q)\right]}
\end{array}\right.
$$

Since the parallel system of the two inverters is a multi-input and multi-output system, the relationship between the output voltage $u_{0 n}$ and the grid-connected current $i_{2 n}$ of the inverters is as follows:

$$
\left(\begin{array}{l}
i_{21} \\
i_{22}
\end{array}\right)=G_{i j}(s) \cdot\left(\begin{array}{l}
u_{01} \\
u_{02}
\end{array}\right)=\left(\begin{array}{ll}
G_{11} & G_{12} \\
G_{21} & G_{22}
\end{array}\right) \cdot\left(\begin{array}{l}
u_{01} \\
u_{02}
\end{array}\right)
$$

From Equations (7)-(9), it can be deduced:

$$
\left\{\begin{array}{l}
i_{21}=G_{11} u_{01}+G_{12} u_{02}=\frac{\left(N+2 Z_{g} P\right) Z_{c 1} u_{01}-\left(M+2 Z_{g} Q\right) Z_{c 2} u_{02}}{2\left[M \times N+Z_{g}(M \times P+N \times Q)\right]}+\frac{N Z_{c 1} u_{01}+M Z_{c 2} u_{02}}{2\left[M \times N+Z_{g}(M \times P+N \times Q)\right]} \\
i_{22}=G_{21} u_{01}+G_{22} u_{02}=\frac{\left(M+2 Z_{g} Q\right) Z_{c 2} u_{02}-\left(N+2 Z_{g} P\right) Z_{c 1} u_{01}}{2\left[M \times N+Z_{g}(M \times P+N \times Q)\right]}+\frac{N Z_{c 1} u_{01}+M Z_{c 2} u_{02}}{2\left[M \times N+Z_{g}(M \times P+N \times Q)\right]}
\end{array}\right.
$$

Then the total current $i_{g}$ of grid connection is:

$$
i_{g}=i_{21}+i_{22}=\frac{N Z_{c 1} u_{01}+M Z_{c 2} u_{02}}{M \times N+Z_{g}(M \times P+N \times Q)}
$$

By comparing the grid-connected current $i_{2 n}$ with the total grid-connected current $i_{g}$, it can be seen that the grid-connected current of the inverter $n$ is composed of two parts, that is, 1 and 2 inverters. A part of the current exists between the inverters and does not flow into the grid. The current of each group of inverters is equal, but in the opposite direction, it is called interactive current. The expression of the interactive current is as follows:

$$
i_{i c}=\frac{\left(N+2 Z_{g} P\right) Z_{c 1} u_{01}-\left(M+2 Z_{g} Q\right) Z_{c 2} u_{02}}{2\left[M \times N+Z_{g}(M \times P+N \times Q)\right]}
$$

The other part of the current flows into the grid. The current of each group of inverters is equal in value and direction, which is called the common current. The expression of the common current is:

$$
i_{\text {com }}=\frac{N \times Z_{c 1} u_{01}+M \times Z_{c 2} u_{02}}{2\left[M \times N+Z_{g}(M \times P+N \times Q)\right]}
$$


The relationship between the interactive current and the common current in the system is shown in Figure 7.

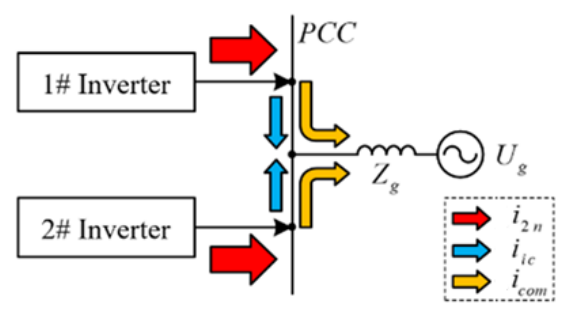

Figure 7. Interactive current and common current for paralleled inverters.

\subsection{Resonance Analysis of Parallel Systems}

From Equation (12) the transfer function of the output voltage $u_{0 n}$ and the interactive current $i_{i c}$ of the inverter bridge is:

$$
\left\{\begin{aligned}
G_{i c 1} & =\frac{i_{i c}}{u_{01}}=\frac{\left(N+2 Z_{g} P\right) Z_{c 1}}{2\left[M \times N+Z_{g}(M \times P+N \times Q)\right]} \\
G_{i c 2} & =\frac{i_{i c}}{u_{02}}=-\frac{\left(M+2 Z_{g} Q\right) Z_{c 2}}{2\left[M \times N+Z_{g}(M \times P+N \times Q)\right]}
\end{aligned}\right.
$$

From Equation (13) the transfer function of output voltage $u_{0 n}$ and common current $i_{\text {com }}$ of the inverter bridge is:

$$
\left\{\begin{array}{l}
G_{c o m 1}=\frac{i_{c o m}}{u_{01}}=\frac{N Z_{c 1}}{2\left[M \times N+Z_{g}(M \times P+N \times Q)\right]} \\
G_{c o m 2}=\frac{i_{c o m}}{u_{02}}=\frac{M Z_{c 2}}{2\left[M \times N+Z_{g}(M \times P+N \times Q)\right]}
\end{array}\right.
$$

From Equations (14) and (15), two resonance frequencies can be obtained respectively:

$$
\begin{gathered}
\omega_{\text {res } 1}=\sqrt{\frac{A+\sqrt{B}}{2 D}} \\
\omega_{\text {res } 2}=\sqrt{\frac{A-\sqrt{B}}{2 D}}
\end{gathered}
$$

where:

$$
\begin{aligned}
& A=C_{1} L_{11}\left(\left(L_{12}+L_{22}\right)\left(L_{12}+L_{g}\right)+L_{12} L_{g}\right)+C_{2} L_{21}\left(\left(L_{11}+L_{12}\right)\left(L_{22}+L_{g}\right)+L_{22} L_{g}\right) \\
& B=\left(C_{1} L_{11}\left(\left(L_{21}+L_{22}\right)\left(L_{12}+L_{g}\right)+L_{12} L_{g}\right)-C_{2} L_{21}\left(\left(L_{11}+L_{12}\right)\left(L_{22}+L_{g}\right)+L_{22} L_{g}\right)\right)^{2}+4 C_{1} C_{2}\left(L_{11} L_{21} L_{g}\right)^{2} \\
& D=L_{11} L_{21} C_{1} C_{2}\left(L_{12} L_{22}+L_{12} L_{g}+L_{22} L_{g}\right)
\end{aligned}
$$

When the same capacity inverters are used in parallel, the resonant frequency is:

$$
\omega_{r e s 1}=\sqrt{\frac{L_{11}+L_{21}}{L_{11} L_{21} C_{1}}}, \omega_{r e s 2}=\sqrt{\frac{L_{11}+L_{21}+2 L_{g}}{L_{11} C_{1}\left(L_{21}+2 L_{g}\right)}}
$$

Figure 8 shows the amplitude-frequency characteristics of $G_{i c}$ and $G_{c o m}$ with the same capacity inverters. From the comparison of Figures 4 and 8, it can be seen that the resonance of the interactive

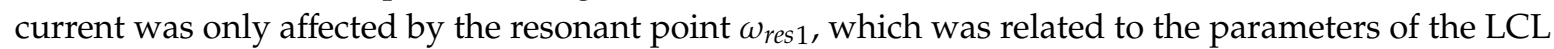
filter and was the same as the resonant frequency of the single inverter in the ideal state, that is, the resonant frequency of the LCL filter itself; and the resonance of the common current was affected by the resonant point $\omega_{\text {res } 2}$, which was not only related to the parameters of the LCL filter, but also related to the grid impedance $L_{g}$. The total impedance of the grid-connected system with $N$ identical inverters 
equally increased by $N$ times [9], and the resonance frequency of the system was the same as that of the common resonance point $\omega_{\mathrm{r}}$.

$$
\omega_{\mathrm{r}}=\sqrt{\frac{L_{11}+L_{21}+2 L_{g}}{C_{1} L_{11}\left(L_{21}+2 L_{g}\right)}}
$$

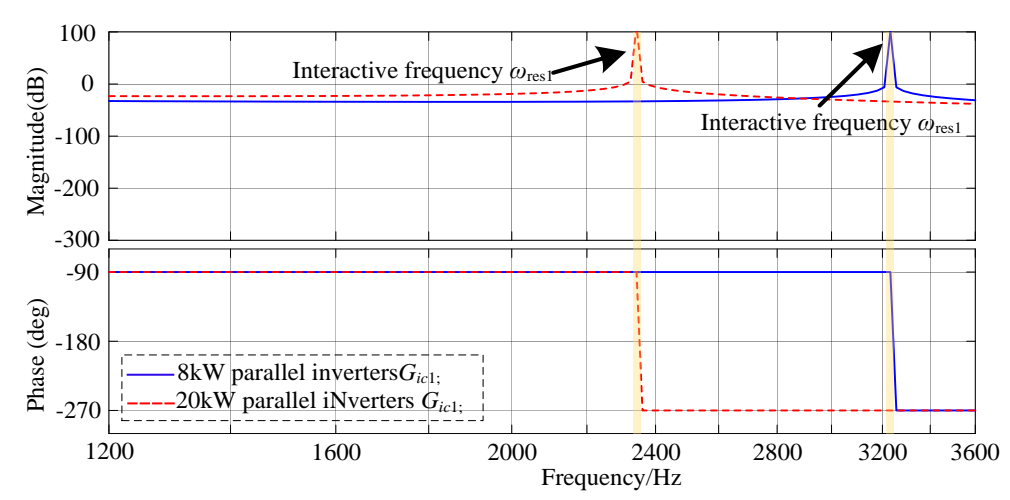

(a)

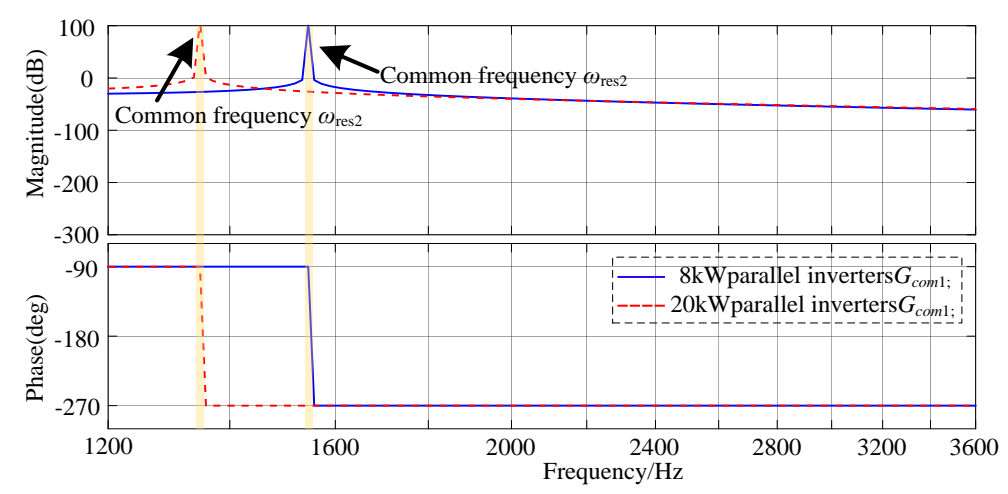

(b)

Figure 8. Amplitude frequency characteristics of parallel system with the same capacity. (a) The Bode diagram of interactive current $G_{i c}$; and (b) the Bode diagram of common current $G_{c o m}$.

Figure 9 shows the amplitude-frequency characteristics of $G_{i c}$ and $G_{c o m}$ with different capacity inverters. Different from the parallel system of the same capacity inverters, when different capacity inverters are connected in parallel, the two resonance points acted on the interactive current and common current simultaneously, and the interactive current resonance $\omega_{\text {res } 1}$ and common current resonance $\omega_{\text {res } 2}$ were offset. The values of the two resonances were correlated with the parameters of LCL filter of each inverter and the impedance $L_{g}$ of the grid.

When a single inverter was connected to the grid, there was only interaction between the inverter and the impedance of the grid. Active damping control can effectively suppress the single resonance. In the parallel system of multi-inverters, each group of inverters adopted independent grid-connected control, and active damping of each group of inverters can suppress common current resonance $\omega_{\text {res } 2 \text {, }}$

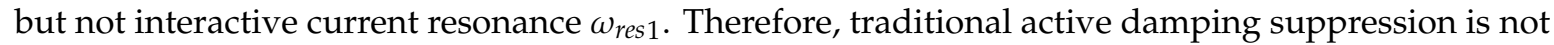
suitable for multi-inverters parallel operation system. 


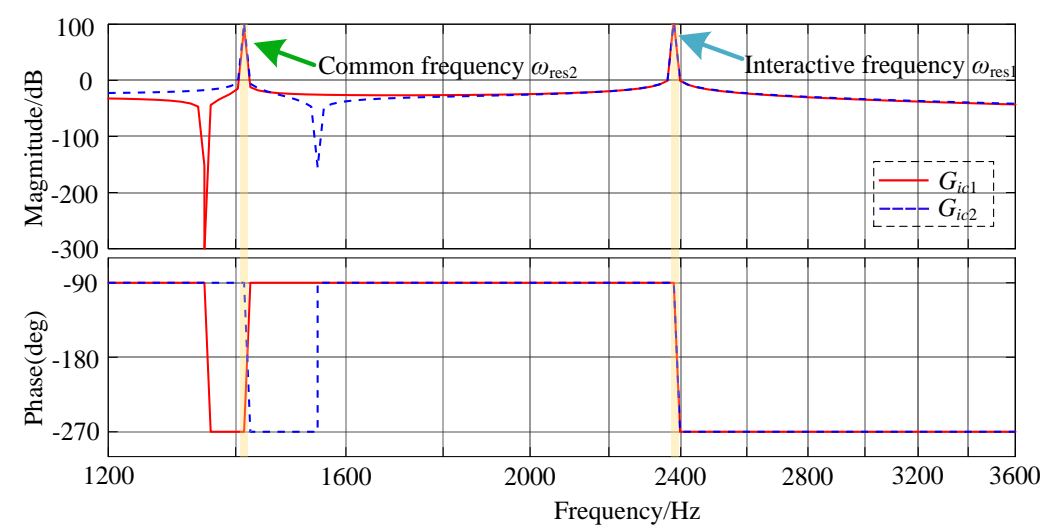

(a)

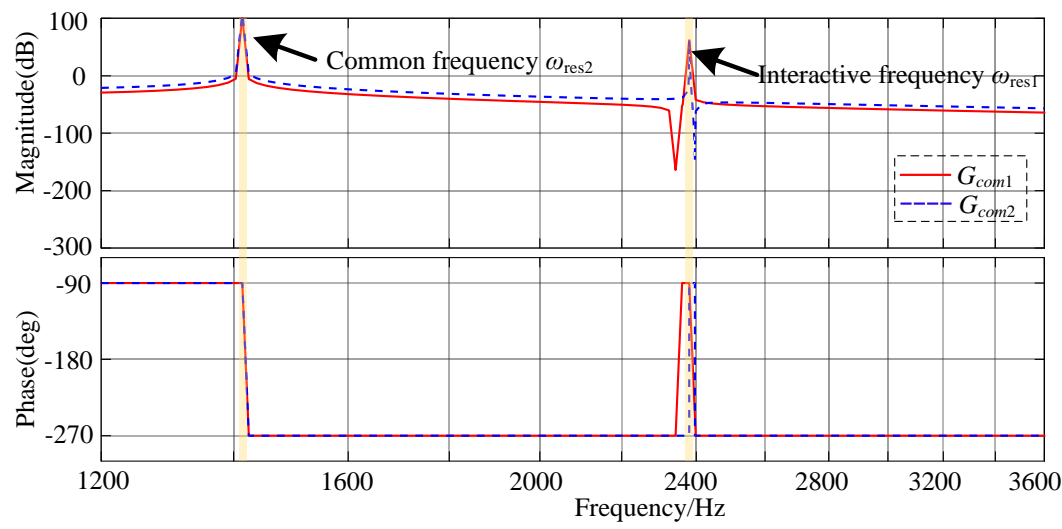

(b)

Figure 9. Amplitude frequency characteristics of parallel system with the different capacity. (a) The Bode diagram of interactive current $G_{i c}$; and (b) the Bode diagram of common current $G_{c o m}$.

\section{Resonance Suppression Strategy for Parallel Systems}

\subsection{Improved System Control Strategy}

In order to solve the multi-resonance problem of the parallel system of two inverters, an active capacitive current damping method based on digital notch filter was adopted in this paper. Figure 10 shows an improved system control block diagram. Based on the active damping suppression of capacitive current, a digital notch filter was designed according to the interactive resonance point, and a current loop controller was introduced to suppress the interactive resonance in the system. When the common resonance point of the system is slightly offset, the capacitive current feedback can still suppress its damping [20]. When the notch frequency of the notch filter was equal to the interactive resonance frequency, the digital notch filter provided an anti-resonant peak opposite to the interactive frequency to offset the positive resonance peak of the system, while in the remaining frequency bands, the gain of the digital notch filter damping was 0 , which does not affect the amplitude-frequency characteristics of the remaining bands. Through the joint action of a digital notch filter and capacitive current feedback active damping, the interactive resonance and common resonance in such systems were suppressed. 


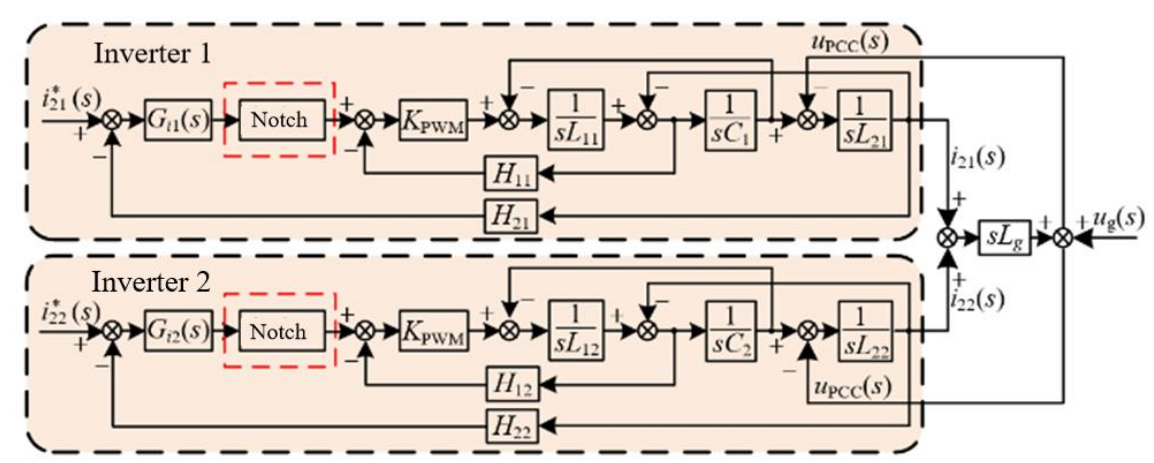

Figure 10. Capacitance current feedback control block diagram based on digital notch.

\subsection{Parameter Design of Current Loop Controller}

When analyzing the amplitude-frequency characteristics of less than or equal to the cut-off frequency $f_{\mathrm{c}}$ of the system, it is generally considered that the capacitor branch is disconnected, and the LCL filter can be simplified to a single L-type filter for analysis. Equation (3) can be approximately equivalent to:

$$
|T(s)|=\left|\frac{H_{i 2} K_{P W M} G_{i}(s)}{s\left(L_{1}+L_{2}+L_{g}\right)}\right|
$$

Proportional integral (PI) regulator is used in current loop controller.

$$
G_{i}(s)=K_{\mathrm{p}}+\frac{K_{i}}{s}
$$

$G_{i}(s)$ can be approximately equivalent to $K_{p}$ when analyzing the amplitude-frequency characteristics of greater than or equal to the system cut-off frequency $f_{\mathrm{c}}$ :

$$
\left|G_{i}\left(j 2 \pi f_{\mathrm{c}}\right)\right|=K_{\mathrm{p}}
$$

At the same time, the amplitude of the system at the cut-off frequency $f_{\mathrm{c}}$ is 1 , that is:

$$
\left|T\left(j 2 \pi f_{\mathrm{c}}\right)\right|=1
$$

From Equations (17)-(20), we can get:

$$
K_{\mathrm{p}} \approx \frac{2 \pi f_{\mathrm{c}}\left(L_{1}+L_{2}+L_{g}\right)}{H_{i 2} K_{P W M}}
$$

The calculation of integral coefficient $K_{i}$ of current loop controller is referred to in [19], which is not described in detail in this paper. The value range of $K_{i}$ is as follows:

$$
\frac{4 \pi^{2} f_{0}\left(L_{1}+L_{2}\right)}{H_{i 2} K_{P W M}} \sqrt{\left(10^{\frac{T_{f o}}{20}} f_{0}\right)^{2}-f_{c}^{2}} \leq K_{i} \leq 2 \pi f_{c} K_{p} \frac{2 \pi L_{1}\left(f_{r}^{2}-f_{c}^{2}\right)-K_{P W M} f_{c} H_{i 1} \tan P_{M}}{2 \pi L_{1}\left(f_{r}^{2}-f_{c}^{2}\right) \tan P_{M}+K_{P W M} f_{c} H_{i 1}}
$$

The values of $K_{p}$ and $K_{i}$ are shown in Table 1. 
Table 1. Main parameters of grid-connected inverters.

\begin{tabular}{ccccc}
\hline Parameters & \multicolumn{2}{c}{ Inverter $\mathbf{1}$} & \multicolumn{2}{c}{ Inverter 2} \\
\hline DC side voltage & $U_{\mathrm{dc} 1}$ & $700 \mathrm{~V}$ & $U_{\mathrm{dc} 2}$ & $700 \mathrm{~V}$ \\
Inverter side inductance & $L_{11}$ & $2.6 \mathrm{mH}$ & $L_{12}$ & $1 \mathrm{mH}$ \\
Filter capacitor & $C_{1}$ & $8 \mu \mathrm{F}$ & $C_{2}$ & $20 \mu \mathrm{F}$ \\
Grid side inductance & $L_{21}$ & $0.7 \mathrm{mH}$ & $L_{22}$ & $0.3 \mathrm{mH}$ \\
Capacity & $P_{1}$ & $8 \mathrm{~kW}$ & $P_{2}$ & $20 \mathrm{~kW}$ \\
Triangular carrier amplitude & $U_{\text {tri1 }}$ & $3 \mathrm{~V}$ & $U_{\mathrm{tri} 2}$ & $3 \mathrm{~V}$ \\
Switching frequency & $f_{\mathrm{sw} 1}$ & $12 \mathrm{kHz}$ & $f_{\mathrm{sw} 2}$ & $12 \mathrm{kHz}$ \\
Sampling frequency & $f_{\mathrm{s} 1}$ & $20 \mathrm{kHz}$ & $f_{\mathrm{s} 2}$ & $20 \mathrm{kHz}$ \\
Capacitance current coefficient & $H_{11}$ & 0.67 & $H_{12}$ & 0.252 \\
Grid-connected current coefficient & $H_{21}$ & 0.24 & $H_{22}$ & 0.09 \\
proportional coefficient & $K_{p 1}$ & 3.8 & $K_{p 2}$ & 3 \\
Integral coefficient & $K_{i 1}$ & 400 & $K_{i 2}$ & 200 \\
Grid voltage & $U_{g}$ & $220 \mathrm{~V}$ & & \\
Fundamental frequency & $f_{o}$ & $50 \mathrm{~Hz}$ & & \\
Power grid impedance & $L_{g}$ & $1 \mathrm{mH}$ & & \\
\hline
\end{tabular}

\subsection{Design of Digital Notch Filter}

The digital notch filter selected in this paper is a typical second-order notch filter. It has the advantages of less computation and good frequency selectivity. Its transfer function expression is as follows:

$$
G_{x}(s)=\frac{s^{2}+\omega_{n}^{2}}{s^{2}+2 \zeta \omega_{n}+\omega_{n}^{2}}
$$

where $\omega_{n}$ is the center angular frequency of the notch filter, the value is the interactive resonance frequency $\omega_{\text {res } 1}$, and $\zeta$ is the damping coefficient. The magnitude of the value affects the anti-disturbance ability of the notch filter. In order to maintain the stability and response speed of the system, the optimum damping ratio $\zeta=0.707$ was adopted.

For the parallel system of two inverters, a group of inverters with different capacities were selected as examples to illustrate. The parameters of a group of inverters are shown in Table 1. Among them, the three-phase full-bridge inverter is controlled by sinusoidal pulse width modulation (SPWM), and $K_{P W M}$ can be approximately expressed as [19]:

$$
K_{P W M}=U_{\mathrm{dcn}} / 2 U_{\text {trin }}
$$

When a group of two identical inverters with $8 \mathrm{~kW}$ capacity are running in parallel, the resonant angle frequency of the digital notch filter is $\omega_{n}=\omega_{\text {res } 1}=15,055 \mathrm{rad} / \mathrm{s}$ as determined by Equation (18). Sampling time was $T=1 \times 10^{-4} \mathrm{~s}$, discretization was performed by the bilinear variation method. The transfer function of the notch filter was:

$$
G_{1}(z)=\left.G_{1}(s)\right|_{s=\frac{2(z-1)}{T(z+1)}}=\frac{18.27 z^{2}-27.47 z+18.27}{26.78 z^{2}-27.47 z+9.75}
$$

Similarly, when two different inverters with a capacity of $8 \mathrm{~kW}$ and $20 \mathrm{~kW}$ were connected in parallel, the resonant angle frequency of the digital notch filter was $\omega_{n}=\omega_{\text {res } 1}=14,955 \mathrm{rad} / \mathrm{s}$, and the transfer function of the notch filter was as follows:

$$
G_{2}(z)=\left.G_{2}(s)\right|_{s=\frac{2(z-1)}{T(z+1)}}=\frac{6.236 z^{2}-3.528 z+6.236}{6.561 z^{2}-3.528 z+5.911}
$$




\section{System Simulation}

In order to verify the correctness and validity of the capacitive current active damping method based on digital notch filter proposed in this paper, the simulation model of the system was established by using MATLAB/Simulink.

\subsection{Grid-Connected Operation of Two Grid-Connected Inverters with the Same Capacity}

When a group of inverters with $8 \mathrm{~kW}$ capacity are parallel connected, the improved control mode is switched to the traditional control mode at $0.2 \mathrm{~s}$. Figure 11 shows the operation state waveforms of each inverter.

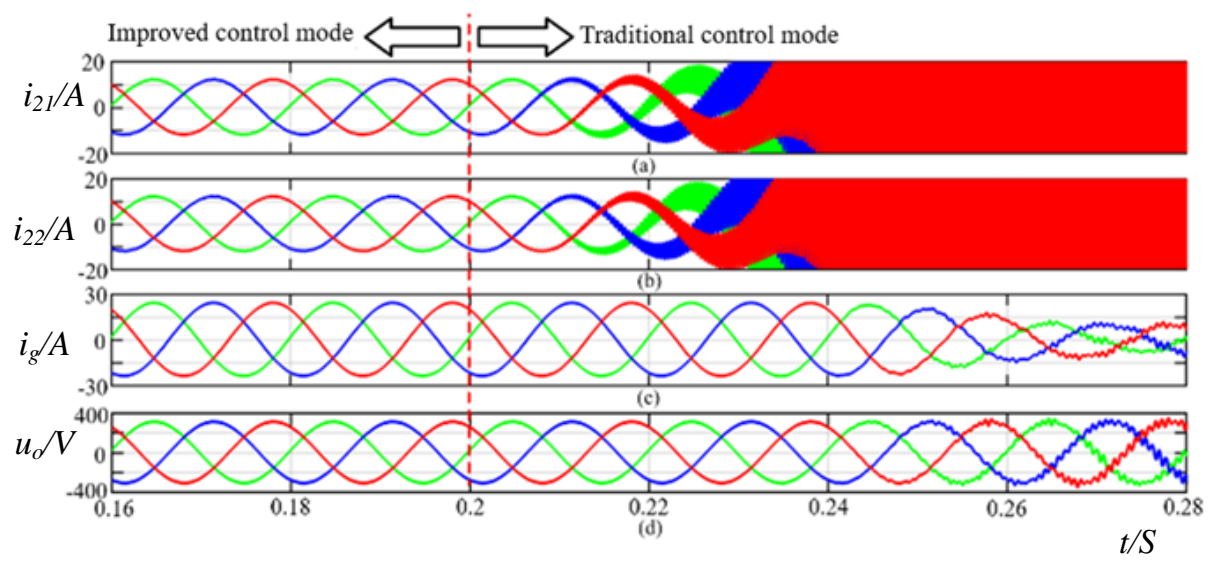

Figure 11. Simulation results of parallel inverters with the same capacity switching from improved control mode to traditional control mode: (a) current waveform of inverter 1; (b) current waveform of inverter 2; (c) total current waveform; and (d) voltage waveform of the point of common coupling (PCC).

By comparison, it can be found that before $0.2 \mathrm{~s}$, the two groups of grid-connected inverters achieved stable operation. At that time, the total harmonic distortion (THD) of the output current of two inverters were $1.51 \%$ and $1.48 \%$, respectively, and the THD of the total grid-connected current was $0.89 \%$, which meet the requirements of grid-connected, and the voltage at the common point PCC is stable. At $0.2 \mathrm{~s}$, when the control mode changed from the improved mode to the traditional mode, the output current of the two sets of grid-connected inverters, the total grid-connected current and the grid-connected common point PCC resonated, and the system was unstable. Therefore, the proposed control strategy can not only eliminate the resonance caused by the interactive current but also improve the quality of grid-connected current waveform and effectively reduce the total harmonic distortion rate of grid-connected current when the system reaches a stable state.

Figure 12 is a comparison of the operation status of a group of inverters when they were in parallel with each other and when the second group of inverters was disconnected at $0.2 \mathrm{~s}$. By comparison, it can be found that before $0.2 \mathrm{~s}$, the two groups of grid-connected inverters achieved stable operation, the grid-connected current met the grid-connected requirements, and the voltage at the common point PCC was stable, while at $0.2 \mathrm{~s}$, when the second group of inverters was off-grid, the first group of inverters only slightly oscillated during switching, and the first group of inverters still operated stably. At that time, the THD of the grid-connected current was $0.99 \%$, and the system still maintained stable operation. As can be seen from Figure 10, when the system was integrated or switched off, the grid-connected current quickly reached its stable state in one cycle and had fast dynamic response-ability. 


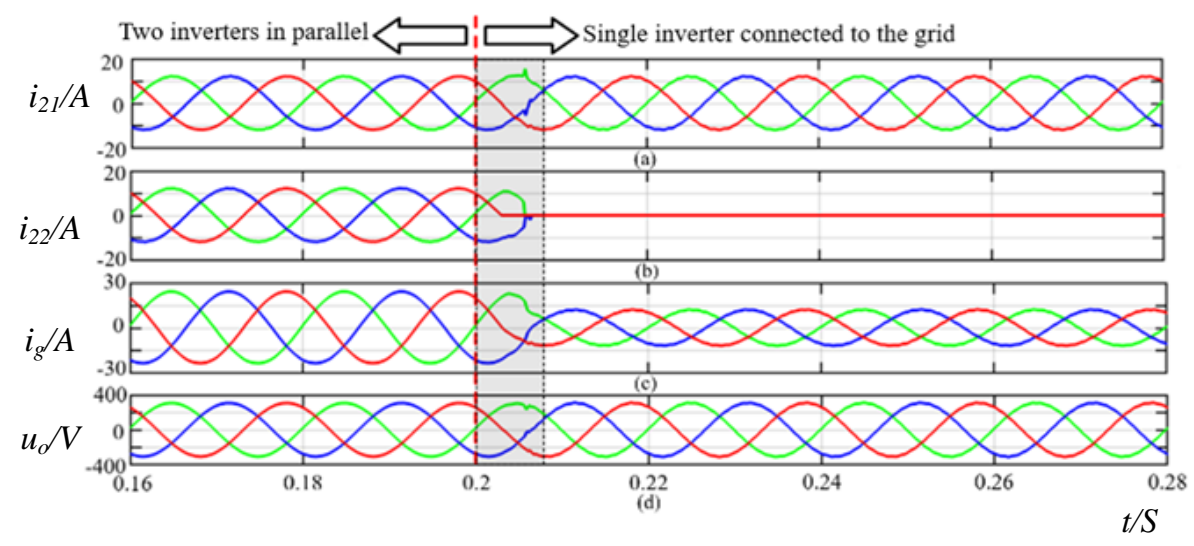

Figure 12. Simulation results of a group of parallel inverters with the same capacity cutting off an inverter: (a) current waveform of inverter 1; (b) current waveform of inverter 2; (c) total current waveform; and (d) voltage waveform of PCC.

\subsection{Grid-Connected Operation of Two Grid-Connected Inverters with Different Capacities}

When two inverters with a capacity of $8 \mathrm{~kW}$ and $20 \mathrm{~kW}$ were used in the parallel operation, the current loop control mode of the two inverters was changed from the improved mode to the traditional mode when the current loop control mode was $0.2 \mathrm{~s}$. The operation state waveform of each inverter is shown in Figure 13.

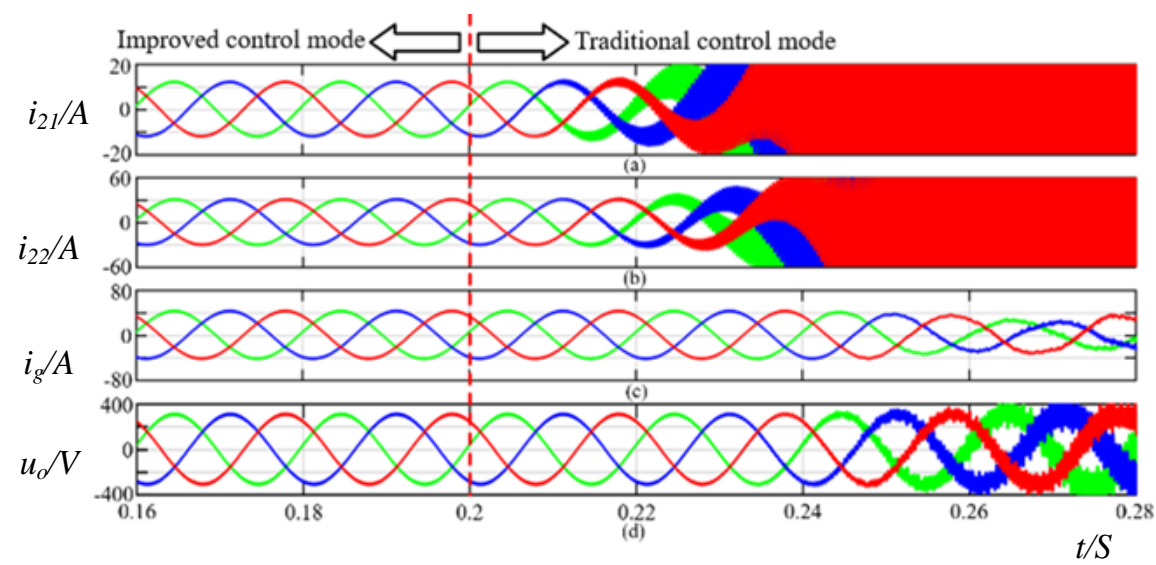

Figure 13. Simulation results of parallel inverters with different capacities switching from improved control mode to traditional control mode: (a) current waveform of inverter 1; (b) current waveform of inverter 2; (c) total current waveform; and (d) voltage waveform of PCC.

By comparison, it can be found that before $0.2 \mathrm{~s}$, the two groups of grid-connected inverters achieved stable operation. At that time, the THD of the output current of a group of inverters were $1.66 \%$ and $1.03 \%$, respectively, and the THD of the total grid-connected current was $0.88 \%$, which met the requirements of grid-connected, and the voltage at the common point PCC of grid-connected was stable. At $0.2 \mathrm{~s}$, when the control mode changed from improved mode to traditional mode, the output current of the two groups of grid-connected inverters was stable. The system was unstable due to the resonance of the total current and the PCC of the grid-connected common point. Therefore, the improved control strategy also achieved good damping suppression effect for parallel inverters with different capacities.

Two groups of different inverters were operated in parallel and switched to single inverters in parallel at $0.2 \mathrm{~s}$. Figure 14 shows the operation status of each inverter. By comparison, it can be found that before $0.2 \mathrm{~s}$, the two groups of grid-connected inverters achieved stable operation, the grid-connected current met the grid-connected requirements, and the voltage at the common point 
PCC was stable, while at $0.2 \mathrm{~s}$, when the second group of inverters was off-grid, the first group of inverters only had slight oscillation during switching, and the first group of inverters still operated stably. At that time, the THD of grid-connected was is $1.02 \%$, and the system still maintained stable operation. It can be seen from Figure 11 that the parallel system of different capacity inverters still had fast dynamic response capability and good dynamic performance when switching the inverters.

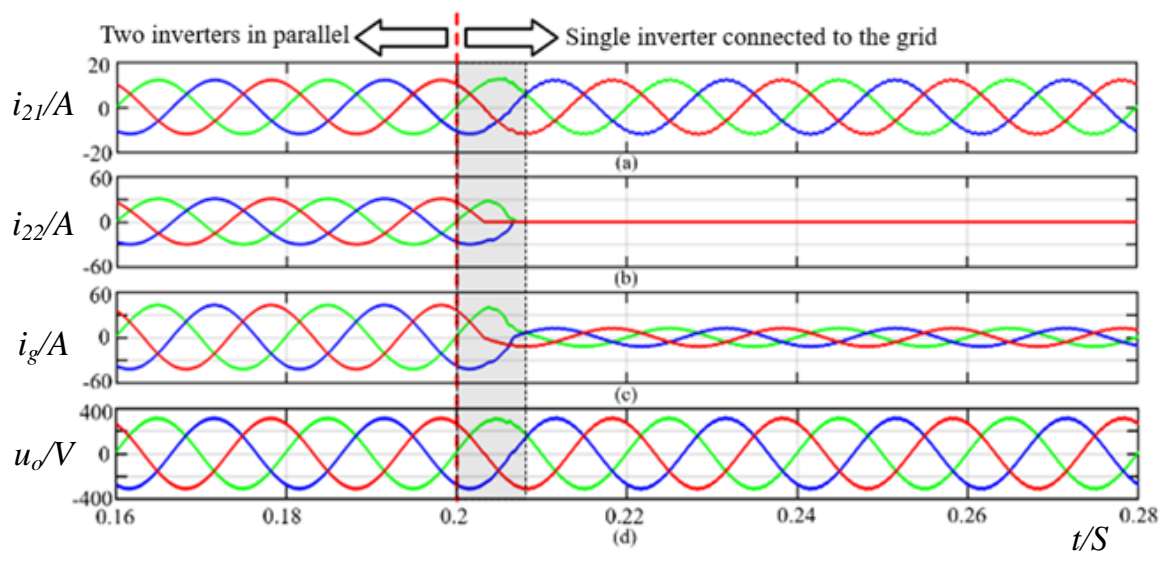

Figure 14. Simulation results of a group of parallel inverters with different capacities cutting off an inverter: (a) current waveform of inverter 1; (b) current waveform of inverter 2; (c) total current waveform; and (d) voltage waveform of PCC.

\section{Conclusions}

In view of the resonance phenomenon of parallel operation of multi-inverters in the weak power grid, the resonance frequency characteristics of parallel inverters with the same and different capacities are studied comparatively. The results show that the interactive resonance between grid-connected inverters is only related to LCL filters in parallel systems with the same capacity, while in parallel systems with different capacity inverters, the interactive resonance between grid-connected inverters is related not only to the LCL filters of each group of inverters but also to the impedance of power grid.

Based on the interactive resonance in a multi-inverters parallel system, a digital notch filter was designed, which was introduced into the traditional capacitive current feedback active damping control to realize the suppression of multi-resonance points and meet the grid-connected requirements of such systems. The simulation results verify the correctness and effectiveness of the proposed strategy.

Author Contributions: H.T. and Y.Z. proposed the analysis method and wrote the manuscript. G.Z. carried out the simulation analysis for the method. Z.Z. edited the manuscript.

Funding: This research was funded in part by Innovative Scientific and Technological Team of Mine Power Electronic Devices and Control in Henan Province and in part by Key Research Projects of Henan Higher Education Institutions (No. 18A410001) and in part by Doctoral foundation of Henan Polytechnic University (No. B2017-19).

Acknowledgments: This work was supported in part by Innovative Scientific and Technological Team of Mine Power Electronic Devices and Control in Henan Province, in part by Key research projects of Henan higher education institutions (No. 18A410001), and in part by Doctoral foundation of Henan Polytechnic University (No. B2017-19). The authors sincerely thank the reviewers for their valuable comments, which improved the quality of the paper.

Conflicts of Interest: The authors declare no conflict of interest.

\section{References}

1. Yang, M.; Luo, A.; Xiao, H.; Ma, F.; Wang, H.; Zhou, X. Circulating Current Analysis and Suppression Method for Multi-inverter Parallel System. Proc. CSU-EPSA 2017, 29, 6-11.

2. Liu, H.; Xu, D.; Wu, J.; Gao, Q.; Wang, X. Analysis, Detection and Mitigation of Resonance in Grid-connected Converter Systems. Proc. CSEE 2016, 36, 1061-1074. 
3. Guo, C.; Yang, H. Optimized LCL-filter Design Considering Stability of Grid-connected Inverters in Weak Grid. Power Syst. Technol. 2018, 42, 949-956.

4. Yang, D.; Ruan, X.; Wu, H. A Virtual Impedance Method to Improve the Performance of LCL-type Grid-connected Inverters under Weak Grid Conditions. Proc. CSEE 2014, 34, 2327-2335.

5. Pan, D.; Ruan, X.; Wang, X.; Bao, C.; Li, X. Controller Design for LCL-type Grid-connected Inverter to Achieve High Robustness against Grid-impedance Variation. Proc. CSEE 2015, 35, 2558-2566.

6. Liu, Y.; Shuai, Z.; Li, Y.; Cheng, Y.; Shen, Z. Harmonic Resonance Modal Analysis of Multi-inverter Grid-connected Systems. Proc. CSEE 2017, 37, 4156-4164.

7. Yao, J.; Tan, Y.; Du, H.; Guo, L.; Zeng, X. Analysis of Resonant Characteristics and Resonance Suppression Strategy of Inverter Parallel System in Islanding Mode. Trans. China Electrotech. Soc. 2016, 31, 199-210.

8. Agorreta, J.; Borrega, M.; Lopez, J.; Marroyo, L. Modeling and control of N-paralleled grid-connected inverters with LCL filter coupled due to grid impedance in PV plants. IEEE Trans. Power Electron. 2011, 26, 770-781. [CrossRef]

9. Yan, G.; Chang, Q.; Huang, Y.; Li, L.; Yu, Y. Analysis on Parallel Operational Characteristics of Multi-Photovoltaic Inverters Connected to Weak-Structured Power System. Power Syst. Technol. 2014, 38, 933-940.

10. He, G.; Xu, D. Resonance suppression for grid-connected multi-inverter based on active damping method. Electr. Mach. Control 2017, 21, 62-68.

11. Zhang, X.; Yu, C.; Liu, F.; Li, F.; Xu, H.; Wang, Y.; Ni, H. Modeling and Resonance Analysis of Multi-paralleled Grid-tied Inverters in PV Systems. Proc. CSEE 2014, 34, 336-345.

12. Lu, M.; Wang, X.; Blaabjerg, F.; Loh, P.C. An Analysis Method for Harmonic Resonance and Stability of Multi-Paralleled LCL-Filtered Inverters. In Proceedings of the 2015 IEEE 6th International Symposium on Power Electronics for Distributed Generation Systems (PEDG), Aachen, Germany, 22-25 June 2015; pp. 1-6.

13. Lu, M.; Wang, X.; Loh, P.C.; Blaabjerg, F. Interaction and aggregated modeling of multiple paralleled inverters with LCL filter. In Proceedings of the 2015 IEEE Energy Conversion Congress and Exposition (ECCE), Montreal, QC, Canada, 20-24 September 2015; pp. 1954-1959.

14. Park, J.-H.; Lee, K.-B. Performance Improvement for Reduction of Resonance in a Grid-Connected Inverter System Using an Improved DPWM Method. Energies 2018, 11, 113. [CrossRef]

15. Yu, J.; Deng, L.; Song, D.; Pei, M. Wide Bandwidth Control for Multi-Parallel Grid-Connected Inverters with Harmonic Compensation. Energies 2019, 12, 571. [CrossRef]

16. Lu, M.; Wang, X.; Loh, P.C.; Blaabjerg, F. Resonance Interaction of Multiparallel Grid-Connected Inverters with LCL Filter. IEEE Trans. Power Electron. 2017, 32, 894-899. [CrossRef]

17. Akhavan, A.; Mohammadi, H.R.; Guerrero, J.M. Modeling and design of a multivariable control system for multi-paralleled grid-connected inverters with LCL filter. Electr. Power Energy Syst. 2018, 94, 354-362. [CrossRef]

18. Yao, W.; Yang, Y.; Zhang, X.; Blaabjerg, F. Digital notch filter based active damping for LCL filters. In Proceedings of the 2015 IEEE Applied Power Electronics Conference and Exposition (APEC), Charlotte, NC, USA, 15-19 March 2015; pp. 2399-2406.

19. Bao, C.; Ruan, X.; Wang, X.; Pan, D.; Li, W.; Weng, K. Design of Grid-connected Inverters with LCL Filter Based on PI Regulator and Capacitor Current Feedback Active Damping. Proc. CSEE 2012, 32, 133-142.

20. Xu, J.; Ji, L.; Ge, X.; Xie, S. LCL-filter Optimization Design with Consideration of Inverter-side Current Feedback Control Impacts. Proc. CSEE 2016, 36, 4656-4665.

(C) 2019 by the authors. Licensee MDPI, Basel, Switzerland. This article is an open access article distributed under the terms and conditions of the Creative Commons Attribution (CC BY) license (http://creativecommons.org/licenses/by/4.0/). 